\title{
Analyzing the Communicative Efficacy of a Soft CLIL Focused Project-based Language Learning EFL Course on Smart Homes
}

\author{
Debopriyo Roy, Peter Kudry and Kagome Naya \\ The University of Aizu, Dept. of Computer Science and Engineering, Japan
}

\begin{abstract}
The rampant urbanization across the world is forcing city planners to be more innovative and creative with technology in how limited resources and amenities are used. Smart homes ( $\mathrm{SH}$ ) technology is one such use. Until now, this has not been a subject for study in the language curriculum, and more so, not as part of the EFL curriculum. This paper discussed a model project-based language learning (PBLL) coursework on SH offered as part of foreign language coursework in a computer science university in Japan in collaboration with a German technical university. This course is aimed at developing students' ability for information comprehension, data analysis, note-taking, summarization, speaking, video design, technical presentations, and poster design, all in English. The paper is a case study on how to make such technical writing/communication courses interesting and engaging for students who see the technology side of a smart city design context but do not necessarily see through the human side of the urban design and usability. This paper is aimed at helping language practitioners offer language courses using a soft-CLIL model that focuses on design thinking, urban planning, language acquisition, and project management all as a package in the pedagogical design, as is often necessary for industrial projects. The idea is to help language practitioners offer coursework that has societal relevance and transfer skills in-built, and is just not focused on language elements in isolation, but develops project management and communication skills as well.
\end{abstract}

\section{Introduction}

CLIL (Content Language Integrated Learning) refers to situations where subjects or topics are taught through a foreign language with the dual-focused aim to teaching both the content and the simultaneous learning of the language (Marsh, 1994). SOFT CLIL is a situation where some language learning is taught with the content, while HARD CLIL is one where language and content are both taught at the same time. As part of this paper, we discussed a SOFT CLIL teaching situation combining a separate graduate and undergraduate course teaching students to handle a technical communication-based $\mathrm{SH}$ project with collaboration between the two different undergrad-graduate student groups, with foreign student groups collaborating as overseas partners. With this framework, the course took a project-based language learning (PBLL) approach within a SOFT CLIL framework. Research in CLIL incorporating PBLL is almost non-existent. This paper highlights one such project which focused on content, group coordination, time management, data management, technical documentation and technical presentation skills as part of overall English communication and project management skills development.

As part of this project, three undergraduate student groups from a third year EFL elective course on information management in a Japanese computer science university effectively collaborated to read, understand, and deliver audio-video presentations, graphics-based projects and text reports on short $\mathrm{SH}$ projects on SH technology and business, using different information management and advertising software and templates. These short two weeks long assignments during the coursework were handled and completed with two graduate students acting as mentors for undergraduate student groups, and then the completed projects were turned over to German graduate student partners from a German university who took the content and then designed ontology and XML metadata for component content management and delivery structures as part of their advanced technical communication coursework. For this entire exercise, the German graduate students communicated with the Japanese graduate students for project-level understanding of the content. The entire package of content on SH (written by graduate and undergraduate Japanese university students in the course) was delivered to the German students, with effective communication and back-andforth information exchange happening along the way. Each undergraduate team had a team leader and the leader coordinated with the graduate student mentor, and the mentor in turn communicated with the German student groups. The undergrad team leaders were in charge of managing their group content, making sure the graduate mentors received it and understood it; the graduate mentors had to write their own reports (as part of their own graduate course on $\mathrm{SH}$ ) making sure the Germans understood the $\mathrm{SH}$ projects (the graduate assignments largely depended on the undergraduate projects), and ensuring smooth communication with their German graduate student partner groups.

Corresponding author: droy@u-aizu.ac.jp 
This entire process happened over a two-months window leading up to an international ACM conference where all the Japanese and German students came face to face and made project presentations. The above collaborative coursework structure on $\mathrm{SH}$ suggest that this is not merely a SOFT CLIL course using standard CLIL-teaching tools; but one which depended a whole lot on project management skills, and intercultural communication at different levels. Language acquisition was expected to happen through diverse collaborative reading, writing, video design, and communication activities.

The next section discussed the value of CLIL, and PBLL, and how the SH technology and business context provides an appropriate platform to contextualize an international project in a PBLL-based SOFT CLIL context. That will help us answer the following research question:

- How could we design groupwork and collaboration within a SOFT CLIL-PBLL framework? How did the graduate-undergraduate-foreign collaborators combine towards handling this international project, and does it provide preliminary indication that some amount of cultural awareness, exposure, experience of project handling, communication, and technical communication skills developed?

- How was SH used as an effective project topic towards building project management skills?

The above two questions were answered through comments documented by the two graduate students who collaborated with the three undergraduate student groups (11 students) and the German student groups (10 students). We explored the above research questions in light of the communication between the graduate students and the undergraduate groups enrolled in the elective English course at the Japanese university, the suggestions made by these graduate student mentors and how they were accepted, initial impressions about group communication and project management skills etc.

\section{Review of the Literature}

Foreign language teaching in a STEM context, ideally should consider the fact that CLIL provides a definitely unique, advantageous and effective pedagogical structure based on the Coyle's 4Cs framework which situates CLIL to be complex and context-sensitive, is based on the general parameters in CLIL such as cognition, culture, content and communication and acknowledges that any CLIL structure should incorporate a specific combination of the parameters above based on needs analysis, and that language as a learning tool operates in three ways: OF-FORTHROUGH (Coyle, 2007; 2008). Another important consideration in EFL teaching is to identify EAP and ESP pedagogy that are compatible with the CLIL ideology and framework. Such planning will generally incorporate feedback and contribution from the content matter experts as well helping to optimize the CLIL teaching framework (Uemura et al., 2019). Research has effectively shown that there is a significant improvement in EFL students' writing skills with CLIL pedagogy, and that students show positive attitude towards the implementation of CLIL in teaching and learning process (Kusmayadi and Suryana, 2017). CLIL is becoming more prevalent in the Japanese educational system and is increasingly seen as an answer to Japan's English language deficiencies. Research data on students' perceptions of the soft CLIL approach at a Japanese junior high school suggest that overall the students have a positive sentiment towards the soft CLIL lessons. The most challenging thing students reported was understanding the native English teachers and English instruction. It's important that native English teachers pay careful attention to their English usage in classes and that teachers and administrators try to find an optimum balance of soft CLIL lessons that complement the institutional needs of the school (Mahoney, 2019). CLIL coursework has been seen to be using many different tools including graphic organizers, hands-on, multimedia, interviews, videos, demonstrations, debates, games, storytelling, flash cards, labeling, visual aids, diagrams, role-plays etc. Specific software use includes Flickr.com, wordpress.com, Bitstripsforschools.com, projectnoah.org iOS/Android App, creately.com, vine.co, tumblr.com,

emojiscience.com, piktochart.com, social bookmarking and curation, educlipper.net, virtual fieldtrips

(Google.com/cultureinstitute), makerspaces, 3D printing and coding etc.

\subsection{Project based Language Learning}

PBL is defined as "an instructional approach that contextualizes learning by presenting learners with problems to solve or products to develop" (Moss \& Van Duzer, 1998). Project-based instruction for language learning is a valuable way to promote the simultaneous acquisition of language, content, and skills, provided that students in academic ESL classes can see the value of learning through projects, which has not always been the case (Beckett and Slater, 2005). PBLL can play a key role in language teaching and what this implies for teachers and learners. PBLL not only allows for a practical and meaningful approach to teaching and assessing language learning; it also promotes effective learning strategies and critical thinking skills (Dooly, 2013). A typical PBLL context could also be analyzed for its efficacy with learner reflections of project work through Activity Theory, where tool-mediated activity is understood as the central unit of analysis for human interaction (Gibbes and Carson, 2014). Research on EFL teaching has aptly demonstrated that in reality, studying English does not necessarily focus on syntactic accuracy or competency in grammar usage. Instead, giving opportunities to students to use as much English as students can in real life contexts should be critically considered, especially for those students who have 
limited chances not only to be exposed to native English speakers, but also the opportunity to use English in their real-life settings. PBL is consistent with this English teaching and learning need. It's now important to explain how $\mathrm{SH}$ is an appropriate topic to explore for $\mathrm{CS}$ majors, both from CLIL and PBLL purposes.

\subsection{The Context of Smart Homes: A Case Study}

A "smart home" can be defined as a residence equipped with computing and information technology which anticipates and responds to the needs of the occupants, working to promote their comfort, convenience, security and entertainment through the management of technology within the home and connections to the world beyond (Aldrich, 2003). This course is important for CS majors for the following reasons:

(1) It's an opportunity to read about and understand important $\mathrm{SH}$ technologies as a digital ecosystem that are otherwise, not covered and taught as part of regular computer science courses.

(2) It's an opportunity to read about and investigate how the society perceives the relevance of such technology, and how should it be advertised as a regular feature, making everyday life easier?

(3) It's an opportunity to investigate the SH business both in Asia and Europe, and this knowledge was used to better communicate with the German partners as part of the coursework.

(4) It's an opportunity to learn about information design and technical writing using some of the standard SOFT CLIL tools, such as brainstorming tools, graphic organizers, storytelling, video design etc.

\section{The Coursework and Methodology}

The course was offered as a $3^{\text {rd }}$ year undergraduate elective with the title Technical Writing for IT Business, in combination with a graduate elective course with the title Technical Writing for Software Engineering. Both were essentially technical writing courses offered for CS majors and with $\mathrm{SH}$ as the central theme revolving around a SOFT CLIL-PBLL pedagogical approach. Since the course topic was focused centrally on $\mathrm{SH}$, the weekly assignments for both the courses were designed such that the graduate assignments to a certain extent depended on the undergraduate assignments; and also, it opened up an opportunity for the undergraduate teams to be mentored by the graduate mentors as and when needed. It's also important to note that none of the students had any course experience on SH related topics; and no English course that included SOFT CLIL and PBLL as a continuum. Both the graduate and undergraduate courses were launched under the same course pocket in Schoology (learning management system) with three central content theme folders, namely (A) Introduction to $\mathrm{SH}$ Concepts (B) $\mathrm{SH}$ Business Worldwide (C) Advertising $\mathrm{SH}$ to Citizens and New Customers.

The folder (A) included short online readings and videos on the introduction to $\mathrm{SH}$ concept (including how it works in daily life) and primary technologies used in the market including Amazon Echo, Google Home and Siri. This folder also included a major journal article on the end user perceptions for SH technology. The folder (B) included a short reading on opportunities and challenges in the Japanese SH market, the value of the European SH market, and potential and opportunities in the Asian SH market. Folder (C) included a template on analyzing advertisements, reading on how to target users of $\mathrm{SH}$ products with Facebook Ads, and $\mathrm{SH}$ video documentaries highlighting different $\mathrm{SH}$ technologies on use in real life.

The major technical communication themes from the language learning perspective were as follows: (A) technical writing essentials such as technical reading, documentation, brainstorming tools etc. (B) technical presentations (C) analyzing advertisements and commercials and (D) technical collaboration using TeamViewer, Slack and Google Docs. The SH course was organized as a one-quarter ( 7 weeks) course including the ACM conference where both the German and the Japanese university groups who collaborated throughout the length of the course came together for joint workshops and presentations of their respective topics, with $\mathrm{SH}$ as the central theme. From the Japanese side, the undergraduate course had three groups with the first group having 4 members, the second group 3 members and the third group 4 members (11 students in total). The undergraduate class had 10 Japanese students and 1 Vietnamese student. All the 3 groups completed the same set of assignments. They were mentored and partnered with two graduate students at the Japanese university on SH. The graduate class had one European student and one Japanese student, both with superior English proficiency. The three undergraduate Japanese groups completed the same bi-weekly assignments separately, but they were overseen and mentored by the graduate students, who also collaborated for their own graduate assignment. The graduate course assignments were similar to the undergraduate ones, but much more intense, investigative with higher level requirements for technical report writing and information design and analysis. The 5 German groups ( 2 members each with 5 groups totaling 10 students) were part of an advanced technical communication and content management course being taught at HSKA, Germany focusing on ontology creation, XML metadata creation, content management and delivery portals. 


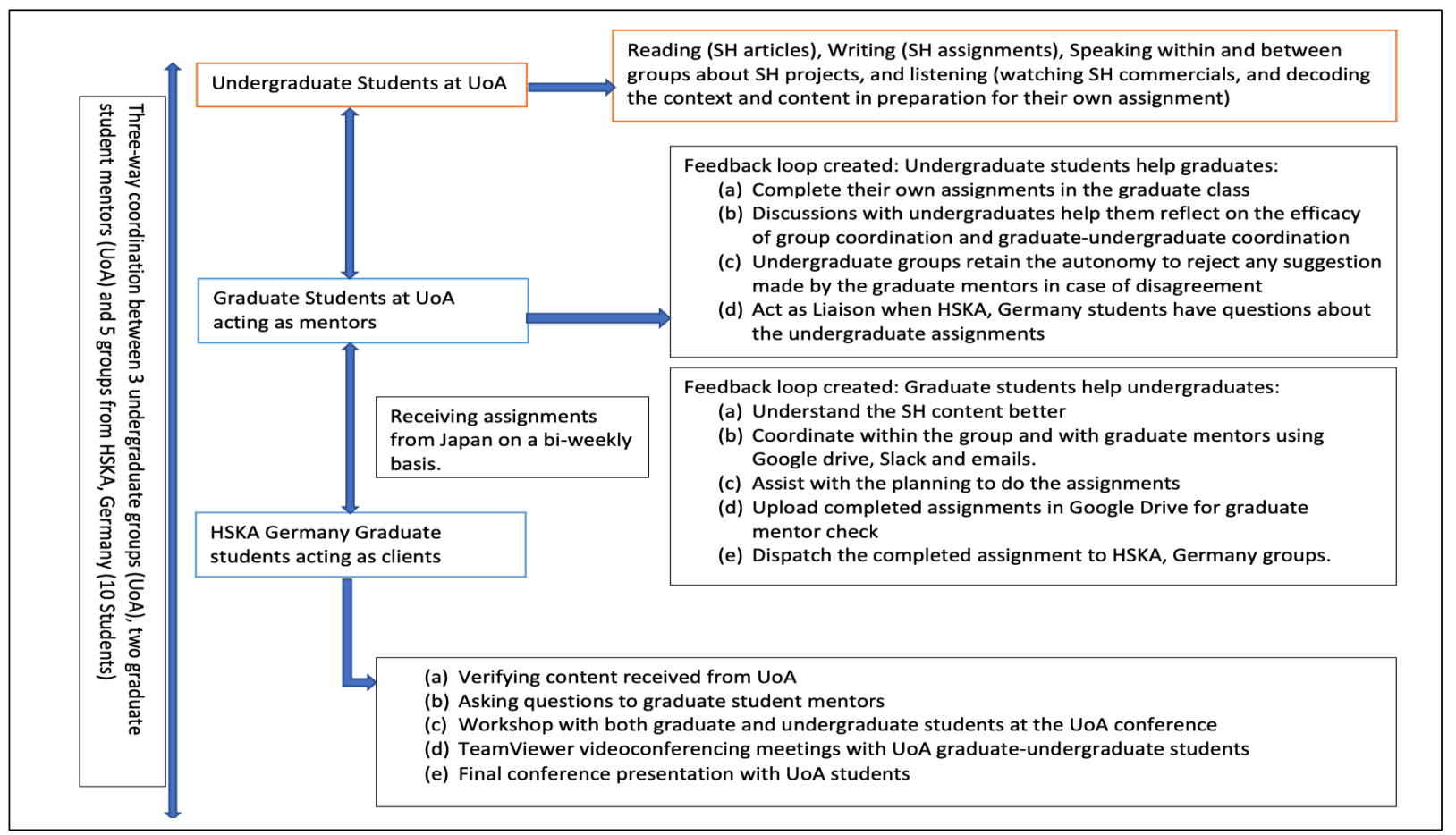

Figure 1. The 3-way Collaboration Schema for Content Comprehension and Exchange

Figure 1 shows the planned collaboration and flow of activities between the undergraduates, graduates and the HSKA, Germany students.

Table 1 provided a layout of the weekly assignments that would help us understand how the SH course was laid out, and how it helped students with English communication skills and group coordination opportunities. The table shows the range of guidelines provided, and the nature of questions that led students to investigate the course notes intensely, and reflect on it when answering assignments.

Table 2 provided an outline of the expected tasks/activities and communication requirements for each assignment.

Table 1. The SH Course Layout

\begin{tabular}{|c|c|}
\hline Assignments & Major Tasks \\
\hline $\begin{array}{l}\text { Week \# 1: } \\
\text { Introduction } \\
\text { to Smart } \\
\text { Homes }\end{array}$ & $\begin{array}{l}\text { Undergraduate: Summarization of Ideas: Key idea of SH, Major technologies of SH, Importance of having SH, } \\
\text { Advertising SH, Examples of SH technology advertised in media, Designing SH t-shirt. } \\
\text { Graduate: Design Newsletter with lucidpress.com - Robust explanation of why society needs SH technologies, Using } \\
\text { Sketchup to draw an illustration of how smart phones are used for SH technology? Evidence of how SH improves } \\
\text { lifestyles, will SH business be successful worldwide, how can media help us advertise SH technologies, critique SH } \\
\text { technology video commercial. }\end{array}$ \\
\hline $\begin{array}{l}\text { 2nd \& 3rd } \\
\text { Week: } \\
\text { Introduce } \\
\text { Two } \\
\text { Different } \\
\text { SMART } \\
\text { HOME } \\
\text { Technologies }\end{array}$ & $\begin{array}{l}\text { Undergraduate: } \\
\text { - Select two technologies/products that you believe are unique and could be appealing to common citizens. } \\
\text { - Design an extensive Sketch-boarding \& Mind Meister Mind Map (2 SEPARATE MAPS) explaining your } \\
\text { group's plan for designing an ADOBE SPARK movie, introducing Technology/Product1 and Technology/Product } \\
2 . \\
\text { Design a short 20-25 Scene Advertising Presentation with Adobe Spark explaining how the above technologies } \\
\text { work in SMART HOMES and make a video commercial for an established company in the field, demonstrating a } \\
\text { movie that appeals to the common people. } \\
\text { Write a 200-words REPORT explaining: } \\
\text { (A) How you have planned and designed the Adobe Spark movie on SH technology using Mind Meister and Sketch } \\
\text { boarding software? (B) Why did you choose the following two technologies/products? Why did you find it interesting } \\
\text { and appealing for common people? }\end{array}$ \\
\hline
\end{tabular}




\begin{tabular}{|c|c|}
\hline & $\begin{array}{l}\text { Graduate: } \\
\text { PART A: A. How do you think a tool such as Mind Meister and Sketchboarding could help commercial designers plan } \\
\text { documentary movies or commercials to conceptualize the concept of smart homes? Is it an effective tool? Give an } \\
\text { example of what will be part of your concept map using these tools for a topic such as "commercializing smart homes"? } \\
\text { PART B: Read the Article marked as "Graduate SH" from this folder. Now, explain the concepts in the article in a } \\
\text { coherent way using Mind Meister and Sketchboarding. We must be able to see the interrelationship between the ideas } \\
\text { and concepts and execution of the plan. You can draw multiple concept maps based on how the ideas are connected and } \\
\text { what makes sense from the perspective of a person trying to understand the concepts for both functionalities and the } \\
\text { structure of the devices/products. } \\
\text { PART C: B. How do you think a tool such as Adobe Spark could help citizens conceptualize the concept of SH? Is it } \\
\text { an effective tool? } \\
\text { Mentoring: B1. Use the work done by the undergrad students to demonstrate what technically qualifies as a good or } \\
\text { bad idea? Critique the work done by undergrads and show how to turn the concept into something really marketable. } \\
\text { WRITE A 200-WORDS REPORT ON THE MENTORING EXPERIENCE, INCLUDING THE PRODUCT, } \\
\text { WORKING WITH IDEAS IN THE GROUP, EXECUTION ISSUES, ETC. }\end{array}$ \\
\hline $\begin{array}{l}\text { 4th \& 5th } \\
\text { Week: Smart } \\
\text { Home } \\
\text { Technology: } \\
\text { An } \\
\text { Exploration } \\
\text { of End-User } \\
\text { Perceptions }\end{array}$ & 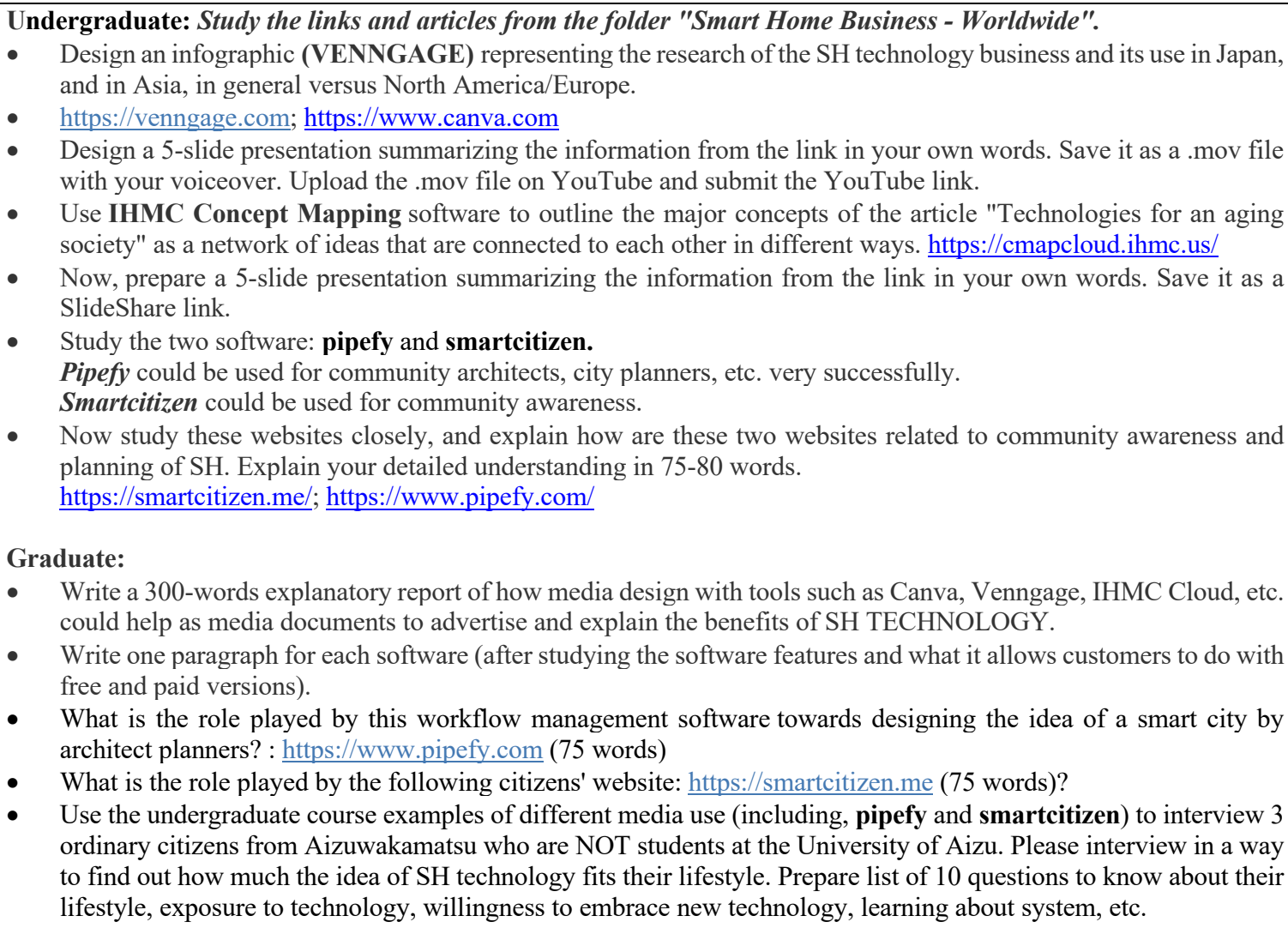 \\
\hline $\begin{array}{l}6^{\text {th }} \& \quad 7^{\text {th }} \\
\text { Week: } \\
\text { ACM } \\
\text { Presentation }\end{array}$ & $\begin{array}{l}\text { Undergraduate: Presentation on topics covered above } \\
\text { Graduate: } \\
\text { - Explain the concept of Ontology in a SH application context; } \\
\text { - } \quad \text { Explain the concepts of the Component Content Management System (CCMS) and CDP and how it could be used } \\
\text { in an SH documentation context } \\
\text { - Explain the role of Ontology for SH planning contexts? } \\
\text { - Conclusion Statement about SH }\end{array}$ \\
\hline
\end{tabular}


Table 2. Outline of Expected Activities and Communication Requirements for Assignments

\begin{tabular}{|l|l|}
\hline \multicolumn{1}{|c|}{ Assignment } & \multicolumn{1}{|c|}{ Expected Tasks and Communication } \\
\hline Week \# 1 & A. Study the concepts related to SH - Reading extensively in English \\
& B. Free writing practice - Writing longer paragraphs explaining the concepts and ideas \\
& C. Newsletter design (graduate class) - Technical design \\
\hline Week \# 2 \& 3 & A. Extensive reading and selecting SH technology \& market analysis \\
& B. Information design exercise with Canva, Mind Meister, Sketchboarding and Adobe Spark \\
& C. Communicate with graduate student mentors and get feedback, revision based on feedback \\
& D. Divide the task among group members; timely completion \\
& E. Response in Slack and TeamViewer \\
& F. Group leaders in charge of communicating the progress with mentors \\
\hline Week 4\&5 & A. Information design exercise with Venngage \\
& B. Analytical reasoning exercise with IHMC Cloud concept mapping \\
& C. Technical presentation design \\
& D. Analytical reasoning with community websites \\
& E. Technical report authoring (graduate) \\
& F. Feedback loop with graduate student mentors and German groups \\
\hline Week $6 \& 7$ & A. Technical presentations design in consultation with graduate mentors \\
& B. Reading advanced journal article on SH \\
& C. Ontology creation (graduate) \\
& D. Coordination with German students in conference workshops on SH \\
& E. International conference presentations \\
\hline
\end{tabular}

\subsection{Data Collection}

When the graduate students acted as mentors for the undergraduate students, it also allowed the two graduate students to reflect on the overall assignments as and how those were completed during each stage of each assignment. The two graduate students collaborated with their undergraduate student groups, gave them advise and suggestions on how to complete the assignment, what the content meant and how they were supposed to approach it when answering. Because of the lack of English language proficiency for most of the undergraduate students (significant lack of Englishspeaking ability), the above-mentioned range of advice and suggestions were important and needed. For each assignment, several class sessions were spent where graduate student mentors took over the class (instead of the instructor), advised and helped the undergraduate students design and write the assignments. In more cases than not, the graduate students were shown the final biweekly assignments by the three undergrad teams before posting it in Schoology and sending it over to the German groups.

Some of the graduate class assignments during the $6^{\text {th }}$ and $7^{\text {th }}$ weeks were independent of the undergraduate class assignments, and were based on the reading and understanding of advanced journal articles on $\mathrm{SH}$. This paper documented the suggestions made by graduate students toward organizing the undergraduate assignments on $\mathrm{SH}$, which in turn was used to answer their own graduate assignments, highlighting content comprehension, the collaboration, where the range of activities definitely lacked timely content delivery to the
German students, and how the content was organized for assignment completion.

\section{Findings}

The findings section included comments made by the two graduate student mentors about how the content was organized for the undergraduate assignments; how the assignments could have been better answered, the actual and expected collaboration between the graduate student mentors and the undergraduate groups, and the collaboration with the German groups.

Project Orientation: We have learned in this course to mimic a project on the theme of $\mathrm{SH}$ with undergraduate students as project members, collaborating German students as clients and we as project managers. As project managers, we were (a) responsible for managing the relationships between all parties /groups concerned, (b) keep track of the work in progress of members, (c) adjusting the amount of work done, (d) exchanging information with clients, and (e) managing delivery times and quality required and expected by clients for such intercultural project collaboration. The results obtained from the quarter-long ( 2 months) project were presented at an ACM international conference by project members (undergraduates) and project managers (2 graduate mentors) in collaboration with the German partner groups. This conference was held at the Japanese university being discussed here. 


\subsection{Overall outlook on the SH content} 4.1.1. 5 Major Topics and the Value of Information Management in Smart Home Market

The Week 2 and 3 assignments outlined the differences between the $\mathrm{SH}$ markets in Europe and Asia. The undergraduate students did create an $\mathrm{SH}$ infographic with major differences between these two. However, the work lacked comprehensive research on the relevant topics.

Suggestions for improvement (Communication with undergraduate groups): Specific differences between the markets were not outlined and there was no explicit statement about the value of information management. Therefore, one topic could outline, for example, the "SH feature demand" differences between Germany and Japan which could then be related to information management. Another point that could have been described in this topic is to reason why the feature sets are different - i.e. many houses lack central heating system due to the fault probabilities caused by earthquakes, while a house without central heating system in Europe is unimaginable. Other topics could talk about the openness of the public towards implementing such technologies in their daily lives. Of course, this is subjective to every person / household but as it can be seen later with the interviews done by the graduate students, there might be differences in customer perceptions about potential use of $\mathrm{SH}$ technology, even within Europe itself. Hence, this section could be differentiated into 4 major topics:

- Differences between European and Asian market for $\mathrm{SH}$

- Relate previous section to information management

- Extend the information management segment with description of openness of public towards adopting smart technologies

- Relate the openness to expandability of both markets in the future

Internal notes for the section above:

- Split the topics into two groups (EU vs Asia) to highlight the importance of the Value of Information Management in the SH Market

- Another reason to split them is because of different demands of "features" between the SHs in EU and Japan,

- Identify the 5 major issues / topics for this chapter from the posters that the undergrads made.

\subsubsection{How $\mathrm{SH}$ as a topic was used to discuss communications and information management?}

We collaborated with undergraduate student groups as a member of this project. First of all, we gained basic knowledge about SH that we treated as the major theme. Also, as a project, we tried to get the members to know each other both within the scope of class sessions, and through email and Slack communication. Next, after learning about the $\mathrm{SH}$ overview, we learned about the various technologies that make it possible. The undergraduate students learnt the use of mind maps and sketch boards for organizing SH advertising content, and learnt how to convey new knowledge to others in a way that is easy for people to understand; and how the end user perceives the SH concept. We investigated whether the undergraduates did understand the context of mind map/sketchboarding use, and created the poster as a report. We helped them more with the schematization of the plan for the mind/concept maps, and less help was needed on the use of the software. We also consulted the undergraduates on how to plan the Adobe Spark movie by designing and planning the different topics, characters/objects and sections in the movie. The results of the entire project were compiled into one presentation and presented at the ACM conference, during the final week of the course. The project managers (grad student mentors) took over the work done by the undergraduate members, and further developed on the idea with advanced information and content management with genres such as ontology and content management and delivery portals (studied at the very basic level), and the final results were presented at the conference by us (the graduate students), as a presentation different from the undergraduate groups.

\subsubsection{Data Collection Process}

The planning for the final technical report (authored by us - the two graduate students) highlighted the importance of the information that includes a short description of the materials that were provided to us exclusively later on in the course, and a short description of what was expected from the undergraduates for each assignment cluster. A great example of an exclusive reading material provided to the graduate class was the journal article on apartment block transformation for elderly people. Subsequently, the report planning also asked for describing the information processing - for example guidance of the undergraduates by graduate students, and how the data output from the undergraduate class was used as input to write graduate class technical reports. This way it will be shown that the data collection was done by 2 different internal factions (undergrads and grads separately) and then shared with an external entity, the HSKA, Germany students, where the information was refined and adjusted to the needs of their (HSKA) study. Therefore, it's important to describe the internal teamwork at UoA and the collaboration with HSKA.

Internal notes before writing the section above:

- Actual communication between the groups making sure that they know about events, classes ... we had Slack ... we sent repeated e-mails as and when needed to make sure the groups are working on the assignment and keeping track of the time... we had Google drive where we supervised the ongoing process. 
- Delivery of the solutions from the grads and undergrads to the HSKA and material organization on the Google drive.

\subsubsection{Findings from Interview / Undergraduate Student Assignments}

In order to understand how commercials for SH should be designed, we (the graduate students) had to do an audience analysis of the different markets to try and understand end user perceptions (this interview was NOT done in collaboration with the undergraduate class). That helped us develop preliminary understanding of the extent to which the design of the Adobe Spark movie, and the poster would be well received by users of SH technology the world over. Reflecting on our own work in the graduate class, this audience analysis interview section should contain differences between the European and Japanese interviewees. It could be outlined that even though the interviewees from Europe were from different countries and belong to two every different age groups, some opinions were similar. However, the willingness of implementation and perception of usefulness of $\mathrm{SH}$ technologies were completely different. What was even more surprising was that the person with a software engineering background was less open towards ownership of an $\mathrm{SH}$ than the interviewee from the clothing industry. The segment about undergraduate student assignment on designing advertising videos could very well be related to the interviews recorded later on. The information design assignment (with Adobe Spark, Canva, Mind Maps, etc.) could very well be a follow-up of the interview assignment for seamless topic transition. On a separate note, undergraduates should definitely be asked about reporting short descriptions of the skills they learned by doing this activity. For example, during the data collection process, students were provided with articles / websites about the different SH technologies which were then processed and the information was transformed into an advertising video.

Internal notes before writing the section above:

- Outline the differences between the interviewees from Eastern / Central and Northern Europe and also write about the possible perception of technology between different age groups.

- Outline the overall perception of SH technologies for the Japanese interviews

- Then relate those differences and opinions stated in the reports to the market descriptions

- Describe that the undergraduate approach to the information design assignments (mind maps, sketchboarding, IHMC cloud map etc.) were according to the guidelines that could be practically used in the process of making real documentation / advertisement and then were verified by the grads.

\subsubsection{Discussions / Implications of this study for technical communication and project-based learning?}

We assumed undergraduates to be project members and German students to be project clients for this course. As a buffer during that time, it was important to sample the client's needs and accurately communicate it to the members. In addition to managing the progress of the members, the situation was communicated to the client, and detailed adjustments were made. By establishing a client, we were able to conduct a simulation experiment closer to the actual project.

\subsubsection{Limitations of the Study / Future Study}

The limitations of this study were that the undergraduate students were not taught proper project management skills (as it was not the course focus) and the undergraduate students could not implement their assignment solutions in real life. Therefore, the success rate of some advertisements they created was a pure estimation. And for the graduate students (us), the course did an evaluation of the project management skills rather implicitly, by seeing progress within the project and perceivable clarity of next milestone among the undergraduate students. In the future, during such a project, the point for greatest importance should be the communication between respective teams and their group members. It has been proven that sometimes, the communication between all interested parties was insufficient. Therefore, in the future, there should be "ice breaking" sessions at the beginning so the team members will be comfortable in each other's presence. Also, communication exercises and training between the teams are highly recommended especially for the sake of the assignment solution quality. This recommendation is due to the observed quality difference between teams, where the members knew each other, as opposed to ones where the team composed of strangers.

Internal notes before writing the section above:

- The project management has not been taught per say, rather practically implemented than theoretically explained.

- In the future, we have to focus on communication as it is the most essential part of any collaboration.

- An example of the above point could be a comparison between the groups that have had different quality levels. For example, the group \#1 was a good example because the group members were familiar with each other and they generally knew what to do, and if they were not sure, they were not afraid to ask questions. 


\subsubsection{Conclusion}

In this course, I learned how to run and manage projects using the theme of SH. As a result, undergraduates learned about the subject, how to share it with members, and how to efficiently communicate the learned knowledge with people, using various media such as posters and videos. Graduate students learned how to manage project members and outcomes, communicate with clients, and organize and better understand things. These results were presented to participants through the conference. The resulting final international conference was a great opportunity to highlight the work done, and also reflect on what could have been better managed - and this was done with joint workshops with the undergraduates, graduate students from UoA and HSKA, Germany. These joint workshops happened during the conference week, in advance of the final conference presentation. This allowed all parties concerned to smoothen the differences in understanding, and clarify how each group thought about their respective projects, and what it meant. It was an opportunity for the HSKA groups to ask us questions and then incorporate the content as part of their own projects. We often went back and forth clarifying the content and it's representation by the Germans in their ontology and metadata

Figures 2a and 2b highlighted the two interfaces - TeamViewer and Slack used extensively during most parts of the course.

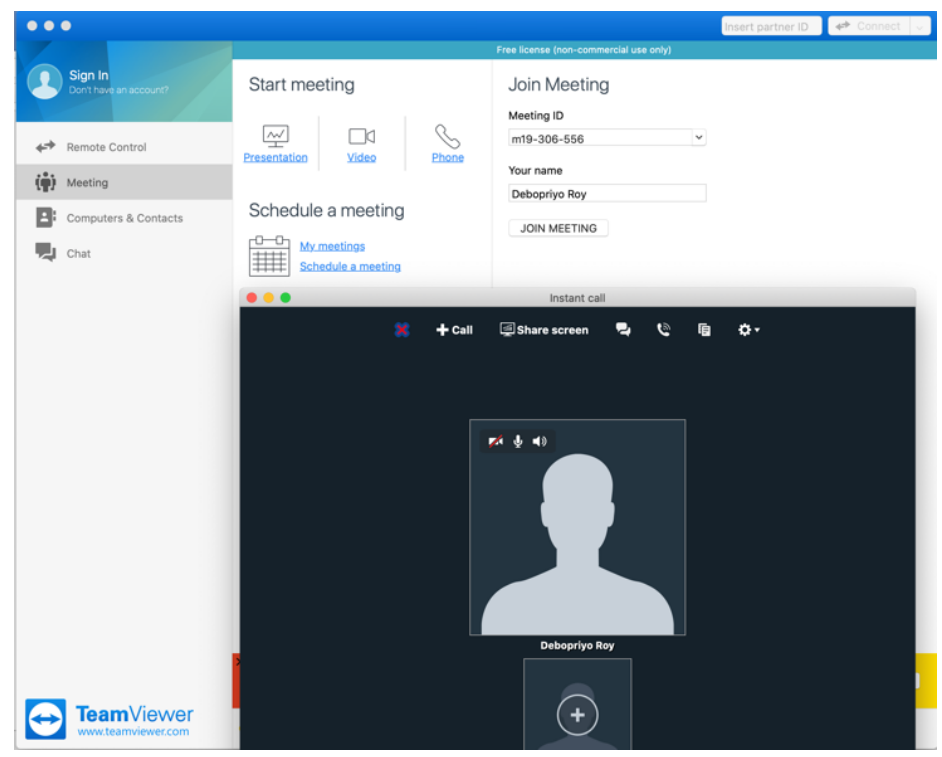

TeamViewer Tasks for the Japanese Groups (as completed)

1. Set up the TeamViewer "Ice-breaking" meeting with the German groups

2. Undergraduate students - self-introduction in English during the meeting with the Germans (inclass practice ahead of the meeting)

3. Graduate students - self-introduction in English during the meeting with the Germans

4. Short project explanation by each undergraduate team leader in English (in-class practice ahead of the meeting)

5. Answering questions in English as asked by the Germans about the project - assisted by the graduate student mentors

6. Communication about the next set of meetings and the expected timeline for project stage completion.

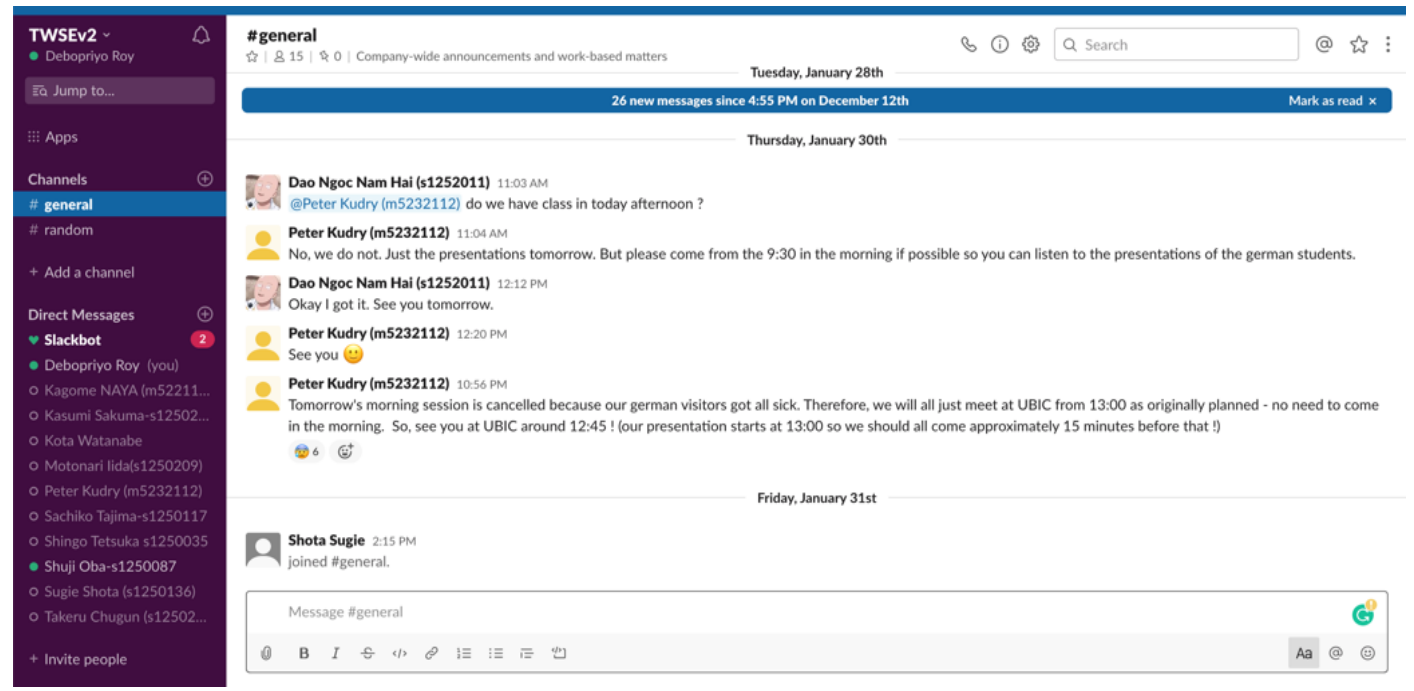

Figure 2a and 2b: TeamViewer (Japan and Germany Teams) and Slack Workspace (Undergrad and Grad Teams in Japan) 


\subsection{Comments on the coordination between graduate-undergraduate teams}

(Week 1): The initial coordination in preparation for writing of this newsletter was done when we discussed various points of the undergraduate equivalent of this assignment. For example, one example is steering the undergraduate groups towards correct content selection and representation, and correcting some of their grammar. Then the draft of the answers, alongside other materials posted on Schoology and from the internet was included in the draft of the final assignment \# 1 response written by the undergrad groups, which was then read by both graduates and constructed into the final graduate newsletter file that was handed in.

Week 2 and 3: The mentoring experience during the completion of the week two and three undergraduate assignments was, from the side of the graduate students, not completely satisfactory. The timeline of these assignments has spanned the Christmas/winter vacation which resulted in poor communication between the students and mentors. For this reason, even though the students were questioned during the holidays, there has not been a significant collaboration between these parties while the assignments were worked on. Rather, the students were questioned about their experience post-deadline and therefore, this section had a rather retrospective feel to it. The overall feeling was that the respective groups were able to evenly distribute the workload among the members of each group. Furthermore, there have not been any disputes over which part should have been done by which student. Most of the group members' decisions were based on either their experience and how well they can utilize their already known skills, or the lack of their experience and how they can lower their skill deficit. Two out of three groups have experienced scheduling difficulties as their hand-ins were turned in later than the prescribed deadline, therefore there was much room for improvement in regards to time management. Time management has been proven to be difficult as when the students were asked if they had more time to complete their assignments, what would they do? A general answer to this question was that they would work on certain parts longer, elevating the quality of their work. The quality of work has also been reviewed by the mentors, particularly, the short videos created in Adobe Spark. If the students decided to include narration in these videos, this was the aspect which showed the lowest quality. In this case, it was not the quality of the videos themselves or quality of the audio recording, it was the English pronunciation which has been, even for bilingual English speakers, difficult to understand. Even though there have been occasional hiccups in quality, planning or execution of this set of assignments, students themselves were satisfied with the work they have submitted. When it comes to the evaluation of the mentors, there have been no complaints, nor request for increased engagement in their work. The amount of mentoring seemed appropriate to them; however, the mentors were left feeling slightly left out and requested higher engagement in communication from their side. This will be in the form of more frequent status updates and immediate access to their workspaces on Google Drive.

\subsection{Note-taking by Graduate Students during Mentoring Activities}

1. Talk to the representatives of the three groups and make notes about their impression of how the work was done, are they happy with it, why did they not communicate with us etc.

2. Tell them strictly that we want to know, and to use the SLACK account we created so that we can follow their work as and when it's updated.

3. Tell them to always post the google doc folder link whenever they create it and start working on the assignment. We also want to be able to check the progress ourselves. So, whenever they create a repository for the latest assignment, they have to make the topic of their group channel a link to the google doc folder.

4. Write three paragraphs (one for each group) where we describe our interactions, their work, content strength, group coordination and also critique the overall quality of their work.

5. Tell the students that we are not TA's, but our results depend on their results too, so we are on the same boat.

6. Get all of the hand-ins from the groups and reply to the e-mail from the German student coordinators

\section{Limitations of the Course and Future Directions}

This paper provided an opportunity to explore how the group coordination took place, and the types of assignments handled that led to development of group communication and project management skills. It's obvious from the reports by the graduate students that the undergraduates did not directly deal with the German students and the communication followed in most cases, through the graduate student mentors. However, direct communication ensued between the graduate student mentors and the undergraduates. A large part of the problem as observed by the course instructor was the lack of confidence in speaking English by the Japanese undergraduate students, and that resulted in deliberate attempt to avoid direct intercultural exposure on the part of the Japanese students. Things were better as the graduate students were confident individuals and they mediated the conversations during video conferencing and when the German student groups visited in the Japanese university campus. I think, in future, at least for this course, we will need to pay closer attention to the points 
raised by the graduate student mentors, including have extended ice-breaking sessions which might include informal and casual meetings before immersing into course-related activities. More videoconferencing sessions with German students would be ideal as well. It's evident from the report above that in more cases, the undergraduates could handle the assignments on their own, and sometimes resisted graduate mentoring, but the larger problem was the avoidance or lack of interest in intercultural communication. Future versions of this course could also consider making the undergraduate students visit local stores and engage in direct client communication and explore the extent to which $\mathrm{SH}$ technologies are sold in the local market, including interviewing store managers to understand the local $\mathrm{SH}$ market. This approach could then act as a prelude or preparation for direct intercultural engagement with the foreign students. However, an important administrative question would be the extent to which this would be possible in a 7-weeks teaching duration.

\section{References}

Aldrich, F. K. (2003). Smart homes: past, present and future. In Inside the smart home (pp. 17-39). Springer, London.

Beckett, G. H., \& Slater, T. (2018). Project-Based Learning and Technology. The TESOL encyclopedia of English language teaching, 1-7.

Coyle, D.: 2007, Content and language integrated learning: Towar ds a connected research agenda for CLIL pedagogies, The International Journal of Bilingual Education and Bilingualism $10: 5,543--562$.

Coyle, D.: 2008, CLIL: A pedagogical approach from the European perspective, in N. Van Deusen-Scholl \& N. Hornberger. (eds.), Encyclopedia of Language and Education, Volume 4: Second and Foreign Language Education (2nd ed.), (97-111). Springer, New York.

Dooly, M. (2013). Promoting competency-based language teaching through project-based language learning. In Competency-based language teaching in higher education (pp. 77-91). Springer, Dordrecht.

Gibbes, M., \& Carson, L. (2014). Project-based language learning: an activity theory analysis. Innovation in language learning and teaching, 8(2), 171-189.

Kusmayadi, Y., \& Suryana, Y. (2017). Improving students' factual report writing skill by using content and language integrated learning (CLIL) method. Indonesian EFL Journal, 3(1), 21-3.

MAHONEY, J. (2019). Student perceptions of soft CLiL lessons in a Japanese junior high school. 自然 . 人間 - 社会 $=$ Nature-people-society, Science and the humanities: 関東学院大学経済学部・経営学部総合 学術論叢, (66), 13-28.

Marsh, D. (1994). Bilingual Education \& Content and Language Integrated Learning. International Association for Cross-cultural Communication, Language Teaching in the Member States of the European Union (Lingua) University of Sorbonne. Paris. Moss, D., \& Van Duzer, C. (1998). Project-Based Learning for Adult English Language Learners. ERIC Digest.

Uemura, T., Gilmour, G. J., \& Costa, L. F. (2019). Testing the Water: Implementing a Soft CLIL Approach for Future Global Engineers at a Japanese University. In Content and Language Integrated Learning in Spanish and Japanese Contexts (pp. 175-201). Palgrave Macmillan, Cham.

\section{About the authors}

Professor Debopriyo Roy is a full professor of technical communication and computer assisted language learning at the Center for Language Research, Dept. of Computer Science and Engineering at the University of Aizu.

Mr. Peter Kudry is a graduate student at the Dept. of Computer Science and Engineering at the University of Aizu.

Miss. Kagome Naya is a graduate student at the Dept. of Computer Science and Engineering at the University of Aizu. 